\title{
Mechano-regulation of mesenchymal stem cell differentiation and collagen organisation during skeletal tissue repair
}

\author{
Thomas Nagel · Daniel J. Kelly
}

Received: date / Accepted: date

\begin{abstract}
A number of mechano-regulation theories have been proposed that relate the differentiation pathway of mesenchymal stem cells (MSCs) to their local biomechanical environment. During spontaneous repair processes in skeletal tissues, the organisation of the extracellular matrix is a key determinant of its mechanical fitness. In this paper we extend the mechano-regulation theory proposed by Prendergast et al (1997) to include the role of the mechanical environment on the collagen architecture in regenerating soft tissues. A large strain anisotropic poroelastic material model is used in a simulation of tissue differentiation in a fracture subject to cyclic bending (Cullinane et al, 2002). The model predicts non-union with cartilage and fibrous tissue formation in the defect. Predicted collagen fibre angles, as determined by the principal decomposition of strainand stress-type tensors, are similar to the architecture seen in native articular cartilage and neoarthroses induced by bending of mid-femoral defects in rats. Both stress and strain based remodelling stimuli successfully predicted the general patterns of collagen fibre organisation observed in vivo. This provides further evidence that collagen organisation during tissue differentiation is determined by the mechanical environment. It is envisioned that such predictive models can play a key role in optimising MSC based skeletal repair therapies where recapitulation of the normal tissue architecture
\end{abstract}

Daniel J. Kelly

Trinity Centre for Bioengineering

Dept. of Mechanical and Manufacturing Engineering

School of Engineering

Trinity College Dublin

Dublin 2, Ireland

E-mail: kellyd9@tcd.ie is critical to successful repair.

Keywords Mechanobiology, fibre remodelling, tissue differentiation, fracture healing, neoarthrosis

\section{Introduction}

Biological tissues, especially those whose primary function is mechanical in nature, such as orthopaedic or cardiovascular tissues, have been shown to be mechanosensitive, i.e. they adapt to changes in their mechanical environment. These adaptations occur during all stages of development - from the embryo to the adult organism. Healing of skeletal injuries has been intensively used for mechanobiological studies. During the healing process the granulation tissue filling the site of injury is infiltrated by mesenchymal stem cells that eventually differentiate into osteoblasts, fibroblasts or chondrocytes etc. and secrete matrix of differing biochemical compositions. Many authors have studied the relationship between this differentiation process and the mechanical environment and proposed mechano-regulation theories. Pauwels $(1941,1960)$ related the mechanical environment, as described by shear stress and hydrostatic stress, to the tissue phenotype. Carter et al $(1988,1998)$ expanded on this idea and used hydrostatic stress and maximum principal strain as regulators, with quantitative boundaries of the mechano-regulation scheme proposed later (Isaksson et al, 2006b). It was used among others in a study where pseudoarthrosis formation was studied in oblique fractures (Loboa et al, 2001). Specifically, this model has been applied frequently in tendon mechano-biology, such as fibrocartilaginous metaplasia formation in tendons wrapping around bony formations (Giori et al, 1993; Wren et al, 2000). Claes et al 
(1998); Claes and Heigele (1999) also used principal strain and hydrostatic stress to predict tissue phenotypes during fracture healing. Recognising the biphasic nature of most skeletal tissues, Prendergast et al (1997); Huiskes et al (1997) based their mechano-regulation algorithm on octahedral shear strain and fluid velocity. It has been successfully used to predict key events during fracture healing (Lacroix and Prendergast, 2002a; Lacroix et al, 2002; Isaksson et al, 2006a), distraction osteogenesis (Isaksson et al, 2007; Boccaccio et al, 2007, 2008) osteochondral defect healing (Kelly and Prendergast, 2005, 2006) and implant integration (Huiskes et al, 1997).

Cullinane et al $(2002,2003)$ have demonstrated that the mechanical environment during bone defect healing can influence both tissue differentiation and the molecular organisation (collagen fibre architecture) of the repair tissue. They showed that cyclic bending applied daily to an experimental mid-femoral defect results in the formation of cartilage as opposed to bone tissue. These neoarthroses exhibited preferred fibre angles consistent with those seen in articular cartilage. Hayward and Morgan (2009) further demonstrated that the patterns of tissue differentiation observed experimentally could be predicted using the mechano-regulation theory of Prendergast et al (1997), providing further evidence to suggest that both strain and fluid flow are key regulators of tissue differentiation. What remains to be elucidated is the exact relationship between the mechanical environment and the molecular organisation of extracellular matrix at the repair site during skeletal tissue differentiation.

A number of theories have been proposed for the remodelling and/or growth of biological tissues (Humphrey and Rajagopal, 2003; Garikipati et al, 2006, 2004). Collagen remodelling has been extensively studied in the context of cardiovascular tissues. In these studies collagen fibres have been assumed to align with respect to a local mechanical regulator such as stress (Taber and Humphrey, 2001; Gleason and Humphrey, 2004; Hariton et al, 2007b,a) or strain (Driessen et al, 2003b,a; Kuhl and Holzapfel, 2007; Driessen et al, 2008). The strain driven remodelling algorithm proposed by Driessen et al (2005) has also been successfully used to predict the collagen architecture in articular cartilage (Wilson et al, 2006a). In studies on fibrocartilage formation in tendons, fibres were also hypothesised to align with respect to the local maximum tensile strain direction (Giori et al, 1993; Wren et al, 2000).

The hypothesis under investigation in this study is that collagen fibres synthesised during tissue differentiation align between the positive principal directions of either local stress or strain tensors. In this paper we extend the mechano-regulation model of Prendergast et al (1997), as implemented by Lacroix et al (2002), to include a fibre reinforced constitutive model for soft tissues, where the organisation of the fibre network is regulated by the mechanical environment. To test the hypothesis, the model will be used to simulate the effect of bending on bone defect repair, and the predicted patterns of differentiation and collagen fibre orientations in the repair tissue will be compared to those observed experimentally by Cullinane et al (2002).

\section{Materials \& methods}

Adaptation of biological tissues is complex and generally includes volumetric growth, synthesis and resorption of extracellular matrix constituents and their reorientation. Here we use the terms remodelling and synthesis loosely to refer to a variety of processes: The reorientation of collagen fibres, the synthesis of new fibrils, their crosslinking etc. Our intention is not to make a clean distinction between the involved mechanisms but to macroscopically and phenomenologically capture the resulting structurally relevant anisotropic effects. In this paper, the term remodelling will be used to represent both modelling and remodelling of the repair tissue architecture in response to the mechanical environment.

\subsection{Constitutive model}

All soft tissues were modelled as fluid saturated porous media. The total mixture stress of a biphasic medium with solid and fluid volume fractions $\phi_{s}$ and $\phi_{f}$ is given as

$$
\begin{aligned}
\boldsymbol{\sigma} & =\boldsymbol{\sigma}_{f}+\boldsymbol{\sigma}_{s} \\
& =-p \phi_{f} \boldsymbol{I}-p \phi_{s} \boldsymbol{I}+\boldsymbol{\sigma}_{s}^{E} \\
& =-p \boldsymbol{I}+\boldsymbol{\sigma}_{s}^{E}
\end{aligned}
$$

where $p$ is the pore pressure and $\sigma_{s}^{E}$ the extra stress in the solid skeleton for which we provide a large strain hyperelastic material model. In hyperelasticity Cauchy stresses can be derived from a Helmholtz free-energy function $\psi(\boldsymbol{C})$ via the relation

$\boldsymbol{\sigma}=\frac{2}{J} \boldsymbol{F} \frac{\partial \psi(\boldsymbol{C})}{\partial \boldsymbol{C}} \boldsymbol{F}^{T}$

where the deformation gradient $\boldsymbol{F}$ has been used to define the right Cauchy-Green tensor $\boldsymbol{C}=\boldsymbol{F}^{T} \boldsymbol{F}$ and the volume ratio $J=\operatorname{det} \boldsymbol{F}$. Due to its porous nature the solid matrix of biphasic tissues is compressible in its bulk properties with respect to the mixture, although 
both the solid phase and the pore fluid are modelled as intrinsically incompressible (Mow et al, 1980). The solid matrix of all tissues was therefore modelled using a compressible Neo-Hookean material law with the strain energy function expressed in terms of the principal invariants $I_{1}(\boldsymbol{C})=\boldsymbol{C}: \boldsymbol{I}$ and $I_{3}(\boldsymbol{C})=\operatorname{det} \boldsymbol{C}=J^{2}$ of the right Cauchy-Green tensor:

$\psi_{\text {iso }}=C_{10}\left(I_{1}-\ln I_{3}-3\right)+D_{2}\left(\ln I_{3}\right)^{2}$

Here $C_{10}$ and $D_{2}$ are material parameters. At small strains they are related to the linear elastic Young's modulus and Poisson's ratio via

$C_{10}=\frac{E}{4(1+\nu)} \quad$ and $\quad D_{2}=\frac{C_{10} \nu}{2(1-2 \nu)}$

While granulation tissue, bone marrow and bone were modelled by this strain energy function alone, fibrous tissue and cartilage were further characterised as anisotropic materials by two fibre directions. These can be identified in the undeformed configuration by the two unit vector fields $\boldsymbol{a}_{0}(\boldsymbol{X})$ and $\boldsymbol{g}_{0}(\boldsymbol{X})$. Subsequently, we omit the dependence on $\boldsymbol{X}$ in our notation. During deformation the fibres are stretched and rotated. Their mapping into the current configuration follows from

$\boldsymbol{a}=\boldsymbol{F} \boldsymbol{a}_{0} \quad$ and $\quad \boldsymbol{g}=\boldsymbol{F} \boldsymbol{g}_{0}$

The fibre stretch $\lambda$ is independent of a rigid body motion and motivates the introduction of the two invariants $I_{4}$ and $I_{6}$ as

$I_{4}=\boldsymbol{I}: \boldsymbol{M C}=\lambda_{a}^{2} \quad$ and $\quad I_{6}=\boldsymbol{I}: \boldsymbol{M}^{\prime} \boldsymbol{C}=\lambda_{g}^{2}$

where the structural tensors $\boldsymbol{M}=\boldsymbol{a}_{0} \otimes \boldsymbol{a}_{0}$ and $\boldsymbol{M}^{\prime}=$ $\boldsymbol{g}_{0} \otimes \boldsymbol{g}_{0}$ have been used. The Helmholtz free-energy is then additively split into isotropic and anisotropic parts:

$\psi=\psi_{\text {iso }}\left(I_{1}, I_{3}\right)+\psi_{\text {aniso }}\left(I_{4}, I_{6}\right)$

The first term already has been defined in eq. (3). For the second term characterising the constitutive behaviour of the collagen fibres we chose an exponential formulation following Holzapfel et al (2002):

$\psi_{\text {aniso }}=\frac{C_{4}}{2 \beta_{a}}\left[e^{\beta_{a}\left(I_{4}-1\right)^{2}}-1\right]+\frac{C_{5}}{2 \beta_{g}}\left[e^{\beta_{g}\left(I_{6}-1\right)^{2}}-1\right]$

The material parameters $C_{4}$ and $C_{5}$ give the fibres a baseline stiffness while $\beta_{a}$ and $\beta_{g}$ describe the stiffening with increasing fibre stretch. If the $\beta$-values are set to zero, a linear fibre model is recovered. Fibres were only allowed to bear tensile loads and were assumed to buckle without stress contributions under compressive loads thus introducing tension-compression nonlinearity into the model.

The described model was implemented into the commercial finite element software package MSC Marc (version 2008r1, MSC.Software Corporation, Santa Ana (CA), USA) via user material interfaces in the context of soil mechanics.

\subsection{Material parameters}

The isotropic material parameters $C_{10}$ and $D_{2}$ were determined via relation (4) from the material parameters used in many previous studies (Isaksson et al, 2006a,b; Byrne et al, 2007; Lacroix and Prendergast, 2002b,a) for bone, bone marrow and granulation tissue. However, due to the switch from isotropic to anisotropic models the material parameters for the remaining soft tissues were reconsidered. Early studies on tissue differentiation during fracture healing often modelled the tissues as single phasic elastic materials neglecting fluid flow (Claes et al, 1998; Claes and Heigele, 1999). The high stiffness values chosen for cartilage in these studies might have been intended to represent a dynamic stiffness. For biphasic models, however, the equilibrium stiffness has to be supplied as a consistent input parameter. Also, these former studies did not take into account tension-compression non-linearities but employed isotropic material laws. For example, a Young's modulus of $10 \mathrm{MPa}$ was commonly chosen for cartilage. Cartilage properties are species-, location- and type dependent. Compressive aggregate moduli of articular cartilage vary between 0.1 and $2 \mathrm{MPa}$ and tensile moduli between 5 and $25 \mathrm{MPa}$ have been reported (Mow and Guo, 2002). We chose an intermediate value of $1 \mathrm{MPa}$ for the Young's modulus of the isotropic ground phase. As many researchers report tensile moduli in split line direction that are roughly 10 fold higher than compressive properties (Roth and Mow, 1980; Akizuki et al, 1987; Huang et al, 2005) we chose a tensile modulus of $10 \mathrm{MPa}$. To transform these values into the parameters for the material model described above a Poisson's ratio for articular cartilage of $\nu=0.167$ was assumed - a value well within the spectrum of reported values (e.g. Jurvelin et al (1997)) and typically used in mechanoregulation studies. Using relation (4) the values for $C_{10}$ and $D_{2}$ can be determined from a compressive Young's modulus of $E_{-}=1 \mathrm{MPa}$. To determine tensile material parameters consider an articular cartilage specimen harvested from the superficial zone parallel to the split-line direction (Roth and Mow, 1980; Akizuki et al, 1987). Both families of fibres were assumed to coincide with the direction of loading and given identical properties. To get a ten times stiffer reaction in tension than 
in compression up to $\approx 20 \%$ strain, the values for the fibre striffnesses were set to $C_{4}=C_{5}=0.964 \mathrm{MPa}$.

The corresponding values for fibrous tissue were approximated to be one fifth of the cartilage values in accordance with previous mechano-regulation studies (Isaksson et al, 2006a,b; Byrne et al, 2007; Lacroix and Prendergast, 2002b).

At physiological loading rates most soft tissues exhibit significant fluid flow independent viscoelasticity. One way to account for the immediate viscoelastic effects without modelling relaxation phenomena is to use a momentary stiffness value instead of an equilibrium modulus. Note however that these values can be specific to certain loading regimes and strain rates. To partially address this uncertainty in soft tissue mechanical properties, we undertook a parameter variation study with 3 sets termed "low" (derived from equilibrium properties), "mid" (intermediate values) and "high" (values previously used in isotropic models were taken as compressive properties for the current fibre reinforced model). The predicted phenotypes and differentiation patterns were compared to those predicted by the traditional approach (i.e. assuming all tissues to be isotropic). Material properties are summarised in table 1. Linear fibre behaviour was assumed, so that $\beta_{a}=\beta_{g}=0$. The fluid bulk modulus of water was used for the pore fluid in all tissues: $\mathrm{K}=2300 \mathrm{MPa}$.

\subsection{Mechano-regulation model}

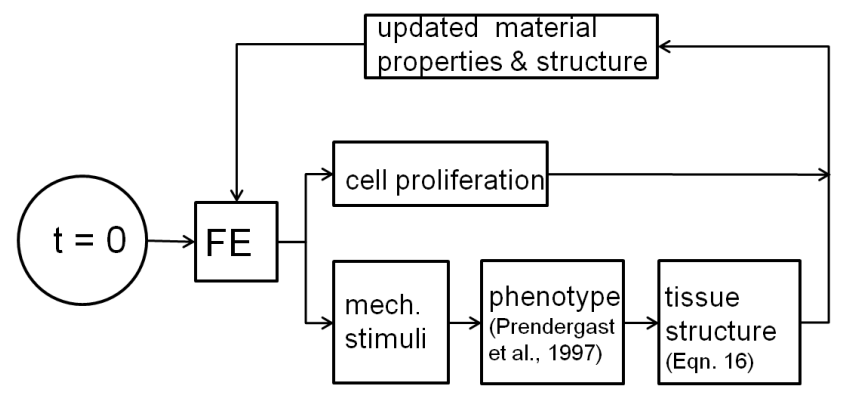

Fig. 1: Iterational loop of the mechano-regulation algorithm to update tissue properties according to predicted differentiation outcomes and architecture.

Mechano-regulation simulations usually follow a common loop (Fig. 1): A typical loading cycle is simulated to compute the regulatory stimuli under present conditions. The implemented regulation algorithm then predicts the tissue's response. Specifically, the mechanical properties at a specific region of the tissue are updated
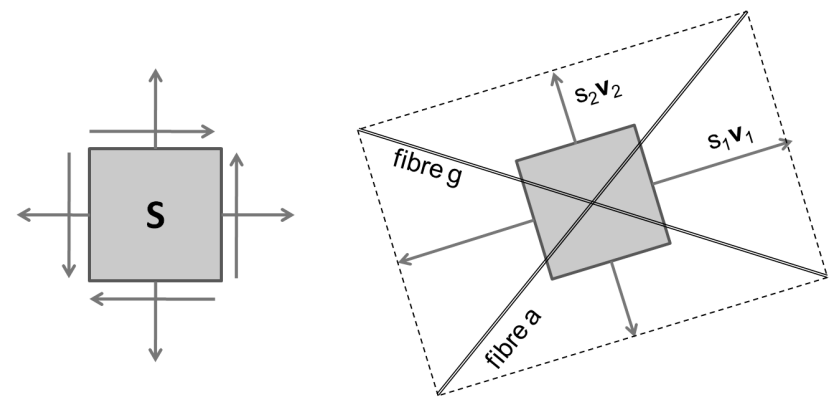

Fig. 2: Stimulus tensor $\boldsymbol{S}$ (left) is transformed into principal space. There, fibre directions are situated between the principal axes depending on the eigenvalues of $\boldsymbol{S}$.

based on the predicted change in tissue phenotype and organisation, as described below. The simulation of the representative loading cycle is then repeated with the updated material properties. We subsequently refer to these loops as iterations $i$. The following mechano-regulation algorithm was implemented in each integration point of the finite element mesh.

At the beginning of the simulation the entire fracture callus was modelled as granulation tissue. Stem cell infiltration from the periosteum, the outer cortical surface and the medullary canal was modelled via a simple diffusion equation:

$\frac{\partial c_{\text {cell }}}{\partial t}=D \nabla^{2} c_{\text {cell }}$

where $c_{\text {cell }}$ is the current cell concentration and $D=$ $0.34 \mathrm{~mm}^{2} \mathrm{~d}^{-1}$ the diffusion coefficient (Lacroix et al, 2002; Andreykiv et al, 2008).

Fluid flow and shear strain were used as mechanoregulatory stimuli for tissue differentiation (Prendergast et al, 1997; Lacroix and Prendergast, 2002b,a; Isaksson et al, 2006a,b). A scalar stimulus $S$

$S=\frac{\gamma}{a}+\frac{v}{b}$

was calculated where $\gamma$ was octahedral shear strain, $v$ fluid velocity. The values of the scaling constants were $a=0.0375$ and $b=3 \mu \mathrm{m}$ (Huiskes et al, 1997). Differentiation into a certain phenotype was then determined according to

$S \begin{cases}\geq 3 & \text { fibrous tissue } \\ \in[1 ; 3) & \text { cartilage } \\ \in[0.267 ; 1) & \text { immature bone } \\ \in[0.011 ; 0.267) & \text { mature bone } \\ <0.011 & \text { resorption }\end{cases}$

The intervals for $S$ were established in Huiskes et al (1997) and later extended to include two bone phases (Lacroix et al, 2002) and bone resorption (Lacroix and 
Table 1: Material parameter sets "low" / "mid" / "high" / "iso". $E_{-}$and $E_{+}$are compressive and tensile Young's moduli, respectively, while for the isotropic parameter set the same modulus $E_{ \pm}$was used in tension and compression. Other variables: $\nu$ - Poisson's ratio, $k$ - permeability, $\phi_{F 0}$ - initial porosity.

\begin{tabular}{|c|c|c|c|c|c|c|c|c|}
\hline property & & $\begin{array}{l}\text { granulation } \\
\text { tissue }\end{array}$ & $\begin{array}{l}\text { fibrous } \\
\text { tissue }\end{array}$ & cartilage & $\begin{array}{l}\text { bone } \\
\text { marrow }\end{array}$ & $\begin{array}{l}\text { immature } \\
\text { bone }\end{array}$ & $\begin{array}{c}\text { mature } \\
\text { bone }\end{array}$ & $\begin{array}{l}\text { cortical } \\
\text { bone }\end{array}$ \\
\hline$E_{-}($low $)$ & {$[\mathrm{MPa}]$} & 0.2 & 0.2 & 1.0 & 2.0 & 1000 & 6000 & 15750 \\
\hline$E_{+}$(low) & {$[\mathrm{MPa}]$} & 0.2 & 2.0 & 10.0 & 2.0 & 1000 & 6000 & 15750 \\
\hline$E_{-}(\operatorname{mid})$ & {$[\mathrm{MPa}]$} & 0.2 & 1.0 & 5.0 & 2.0 & 1000 & 6000 & 15750 \\
\hline$E_{+}(\operatorname{mid})$ & {$[\mathrm{MPa}]$} & 0.2 & 10.0 & 50.0 & 2.0 & 1000 & 6000 & 15750 \\
\hline$E_{-}$(high) & {$[\mathrm{MPa}]$} & 0.2 & 2.0 & 10.0 & 2.0 & 1000 & 6000 & 15750 \\
\hline$E_{+}($high $)$ & {$[\mathrm{MPa}]$} & 0.2 & 20.0 & 100.0 & 2.0 & 1000 & 6000 & 15750 \\
\hline$E_{ \pm}($iso $)$ & {$[\mathrm{MPa}]$} & 0.2 & 2.0 & 10.0 & 2.0 & 1000 & 6000 & 15750 \\
\hline$\nu$ & {$[-]$} & 0.167 & 0.167 & 0.167 & 0.167 & 0.3 & 0.3 & 0.3 \\
\hline$k$ & {$\left[\frac{m m^{4}}{N s}\right]$} & $1 \cdot 10^{-11}$ & $1 \cdot 10^{-11}$ & $5 \cdot 10^{-12}$ & $1 \cdot 10^{-11}$ & $1 \cdot 10^{-10}$ & $3.7 \cdot 10^{-10}$ & $1 \cdot 10^{-14}$ \\
\hline$\phi_{F 0}$ & {$[-]$} & 0.8 & 0.8 & 0.8 & 0.8 & 0.8 & 0.8 & 0.04 \\
\hline
\end{tabular}

Prendergast, 2002a). Mechanical properties of the resulting differentiating tissue were calculated using a rule of mixtures. The following equations use the Young's modulus as an example. However, the described approach was followed for all material properties. Following the computational smoothing procedure from Lacroix and Prendergast (2000) to avoid numerical instabilities and account for the time delay between stimulus and MSC differentiation, the Young's modulus of differentiated tissue in the next iteration $E_{n+1}^{\text {diff }}$ is determined as the average from the Young's moduli $E_{i}$ of the tissue phenotypes during the last ten iterations.

$E_{n+1}^{\operatorname{diff}}=\frac{1}{10} \sum_{i=n-9}^{n} E_{i}$

Employing the rule of mixtures again, final mechanical properties (e.g. $\left.E_{n+1}\right)$ in an integration point are obtained as a weighted average of the properties of the granulation tissue and the differentiated tissue:

$E_{n+1}=\frac{c_{\max }-c_{\text {cell }}}{c_{\max }} E_{\text {gran }}+\frac{c_{\text {cell }}}{c_{\max }} E_{n+1}^{\text {diff }}$

where $c_{\text {cell }}$ is the current and $c_{\max }$ the maximum cell concentration.

Fibre directions were updated equivalently to eq. (12). The unit vectors designating the preferred directions in the following iteration $\boldsymbol{a}_{0, n+1}$ and $\boldsymbol{g}_{0, n+1}$ were thus obtained via

$\boldsymbol{a}_{0, n+1}=\frac{\sum_{i=n-9}^{n} \boldsymbol{a}_{0, i}}{\left|\sum_{i=n-9}^{n} \boldsymbol{a}_{0, i}\right|} \quad$ and $\quad \boldsymbol{g}_{0, n+1}=\frac{\sum_{i=n-9}^{n} \boldsymbol{g}_{0, i}}{\left|\sum_{i=n-9}^{n} \boldsymbol{g}_{0, i}\right|}$

as the average of the predicted unit vectors from the last ten iterations, $\boldsymbol{a}_{0, i}$ and $\boldsymbol{g}_{0, i}$. Prior to summation the directional sense of the vectors was modified to yield a non-negative scalar product:

$\left(\sum_{i=n-9}^{n-k} \boldsymbol{a}_{0, i}\right) \cdot \boldsymbol{a}_{0, n-k+1} \geq 0 \quad$ with $\quad k \in[1,8]$.

Fibres were assumed to align between the positive principal directions of a symmetric stimulus tensor $\boldsymbol{S}$ (see Fig. 2). Consider the spectral decomposition of $\boldsymbol{S}$

$\boldsymbol{S}=\sum_{j=1}^{3} s_{j} \boldsymbol{v}_{j} \otimes \boldsymbol{v}_{j} \quad$ with $\quad s_{1} \geq s_{2} \geq s_{3}$

where $s_{j}$ are the eigenvalues of $\boldsymbol{S}$ and $\boldsymbol{v}_{j} \otimes \boldsymbol{v}_{j}$ the basis of its eigenvectors. In case of $\boldsymbol{S}$ being a material tensor, predicted fibre directions immediately follow from

$\begin{aligned} \boldsymbol{a}_{0, i} & =\frac{s_{1} \boldsymbol{v}_{1}+s_{2} \boldsymbol{v}_{2}+s_{3} \boldsymbol{v}_{3}}{\sqrt{s_{1}^{2}+s_{2}^{2}+s_{3}^{2}}} \\ \boldsymbol{g}_{0, i} & =\frac{s_{1} \boldsymbol{v}_{1}-s_{2} \boldsymbol{v}_{2}-s_{3} \boldsymbol{v}_{3}}{\sqrt{s_{1}^{2}+s_{2}^{2}+s_{3}^{2}}}\end{aligned}$

where only tensile eigenvalues $s_{j}$ are used. If all principal stresses or stretches are non-tensile, then current fibre directions are kept. If only one eigenvalue is tensile, then both fibre directions coincide with the corresponding eigenvector. The resulting vectors from eq. (16) where then used to update fibre orientation in the next iteration via eq. (14).

In case of $\boldsymbol{S}$ being a spatial tensor, fibre directions in the current configuration were driven by the spatial stimulus

$\begin{aligned} \boldsymbol{a}_{i} & =\frac{s_{1} \boldsymbol{v}_{1}+s_{2} \boldsymbol{v}_{2}+s_{3} \boldsymbol{v}_{3}}{\sqrt{s_{1}^{2}+s_{2}^{2}+s_{3}^{2}}} \\ \boldsymbol{g}_{i} & =\frac{s_{1} \boldsymbol{v}_{1}-s_{2} \boldsymbol{v}_{2}-s_{3} \boldsymbol{v}_{3}}{\sqrt{s_{1}^{2}+s_{2}^{2}+s_{3}^{2}}}\end{aligned}$

However, the update of the fibre directions (eq. (14)) took place in the stress free reference configuration. The predicted fibre angles were therefore pulled back and 


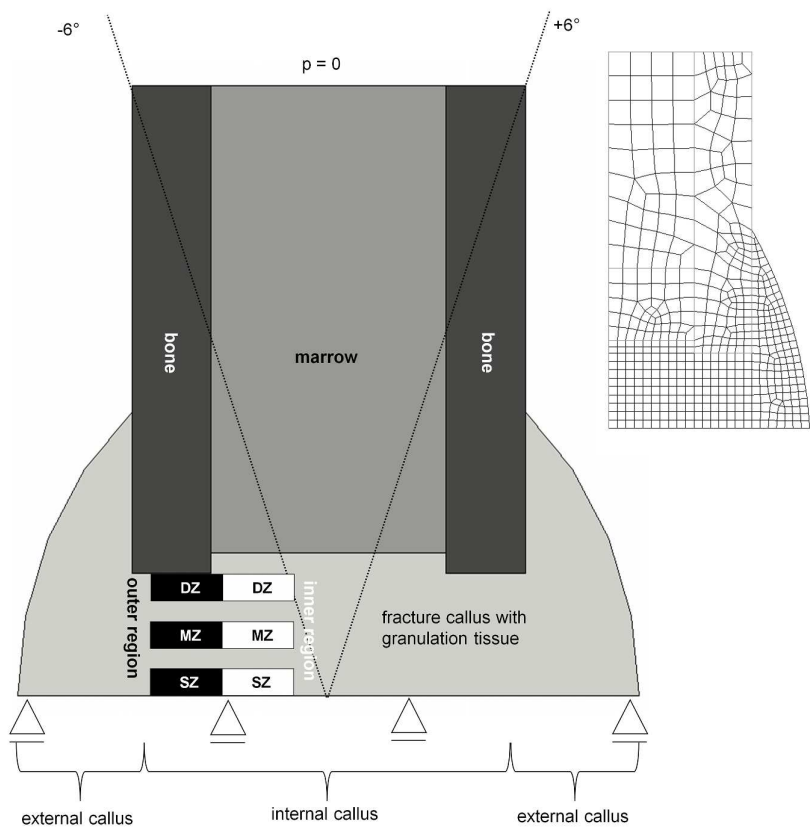

Fig. 3: Schematic of geometry. Boundary conditions and initial state of fracture model. Inner and outer regions of interest within the internal callus are 1: Superficial zone (SZ). 2: Middle zone (MZ). 3: Deep zone (DZ). Each zone was $0.2 \mathrm{~mm}$ high and $1 \mathrm{~mm}$ wide. Half the meshed geometry shown in inlay in top right.

normalised using

$\boldsymbol{a}_{0, i}=\frac{\boldsymbol{F}^{-1} \boldsymbol{a}_{i}}{\left|\boldsymbol{F}^{-1} \boldsymbol{a}_{i}\right|} \quad$ and $\quad \boldsymbol{g}_{0, i}=\frac{\boldsymbol{F}^{-1} \boldsymbol{g}_{i}}{\left|\boldsymbol{F}^{-1} \boldsymbol{g}_{i}\right|}$

and only then fed into eq. (14).

In this paper we examined three possible phenomenological stimuli for fibre reorientation - the material right Cauchy-Green tensor $\boldsymbol{C}$ as well as two spatial stress tensors: The solid extra stress $\sigma_{s}^{E}$, which is directly determined from the material model via the solid matrix deformation gradient, and the total stress in the solid $\boldsymbol{\sigma}_{s}=\boldsymbol{\sigma}_{s}^{E}-p \phi_{s} \boldsymbol{I}$, which also includes the fraction of the pore pressure born by the solid phase.

\subsection{Geometry \& discretisation}

The experimental study by Cullinane et al $(2002,2003)$ was investigated with the extended mechano-regulation theory. An idealised geometry of a rat femor with a $3 \mathrm{~mm}$ fracture gap was created (see Fig. 3). A plane strain finite element model was used to simulate $\pm 6^{\circ}$ bending for 24 days, the time period of loading investigated by Hayward and Morgan (2009).

Fibre angles were measured in Cullinane et al (2003) where "The superficial zone was determined as the area immediately under the cartilage surface, the deep zone was the area immediately adjacent to the underlying bone, and the intermediate zone was exactly half way between the deep and superficial zones". We defined our zones accordingly (see Fig. 3). Fibre angels where averaged in these zones. Two regions of interest were defined in the internal callus: An inner and an outer region as illustrated in Fig. 3.

The geometry was discretised using 1036 eight-noded isoparametric elements with biquadratic interpolation of displacements $(\boldsymbol{u})$ and bilinear interpolation of the pore pressure $(p)$ (MSC, 2008b). A two-field variational approach was adopted using a mixed $\boldsymbol{u}-p$ formulation. The numerical results was obtained via a Newton-Raphson solution strategy (MSC, 2008a). The boundary conditions are shown in Fig. 3.

\subsection{Simulations}

The following simulations were performed. To assess the distribution of tissue phenotypes compared to previous models that assumed isotropy a simulation without a fibre reinforced constitutive model (parameter set $E_{i s o}$ ) was run. In the following nine simulations the three parameter sets "low", "mid" and "high" were each combined with three fibre orientation stimuli: (1) the right Cauchy-Green tensor $\boldsymbol{C}$ (strain driven remodelling, material tensor); (2) the solid extra stress $\boldsymbol{\sigma}_{s}^{E}$ (Cauchy stress driven remodelling, spatial tensor) and (3) the total solid stress $\boldsymbol{\sigma}_{s}$.

\subsection{Angle averaging}

During postprocessing average angles in an area were obtained via the vector summation

$\overline{\boldsymbol{a}}=\frac{1}{N} \sum_{k=1}^{N} \boldsymbol{a}_{0, k}$

and extracting the resulting angle from $\overline{\boldsymbol{a}}$. This angle was defined in the interval $\bar{\varphi} \in\left(-90^{\circ} ; 90^{\circ}\right]$ around the horizontal axis. Note the similarity of equations 14 and 19 where the difference lies in the normalisation condition. While both yield the same direction for a given set of vectors, eq. 14 always yields a vector of unit length and eq. 19 one of unit length or less. This deviation from unit length $\left(|\overline{\boldsymbol{a}}|=1\right.$ would occur if all vectors $\boldsymbol{a}_{0, k}$ were co-linear) was used to compute the circular standard deviation $\sigma_{c}$ used in directional statistics (see e.g. Fisher (1993)):

$\sigma_{c}=\sqrt{-2 \ln |\overline{\boldsymbol{a}}|}$ 


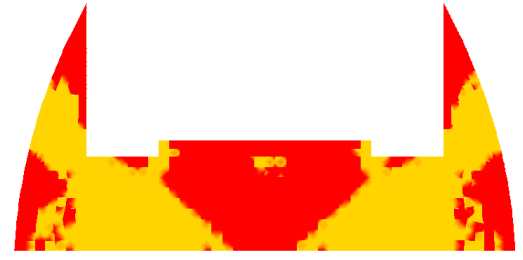

(a) isotropic, high

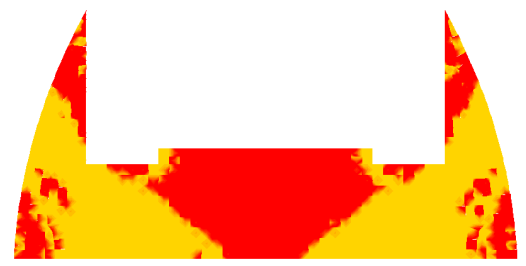

(c) $\boldsymbol{C}$, low

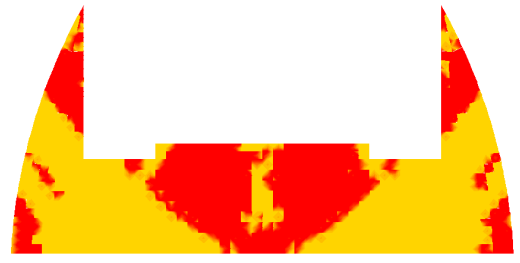

(f) $\boldsymbol{\sigma}_{s}^{E}$, low

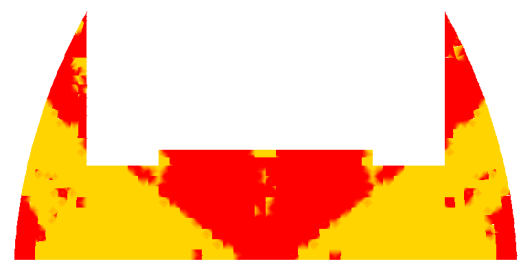

(i) $\boldsymbol{\sigma}_{s}$, low

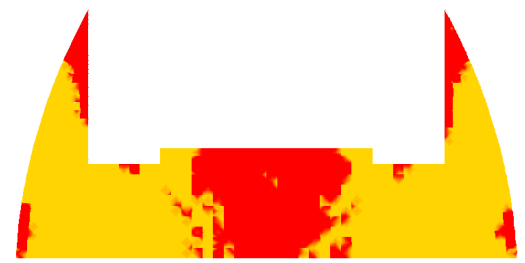

(d) $C$, mid

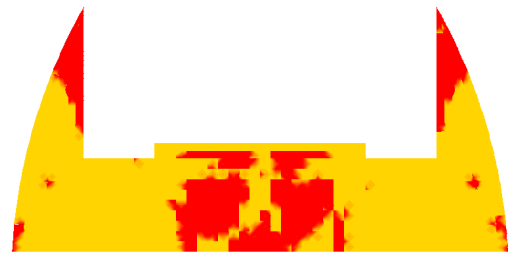

(g) $\boldsymbol{\sigma}_{s}^{E}$, mid

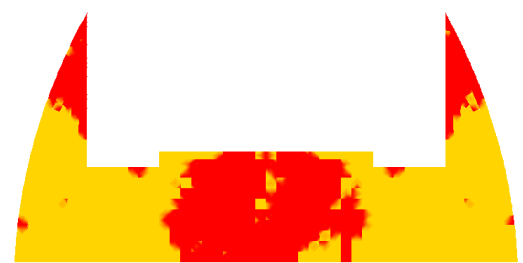

(j) $\boldsymbol{\sigma}_{s}$, mid fib

cart

(b) legend

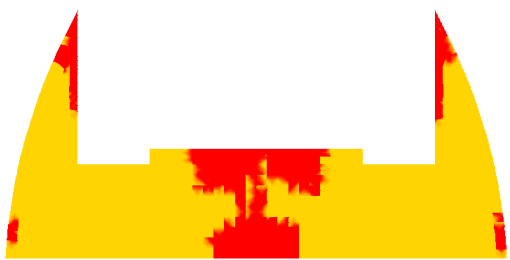

(e) $\boldsymbol{C}$, high

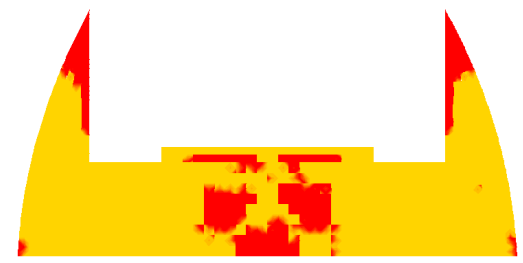

(h) $\sigma_{s}^{E}$, high

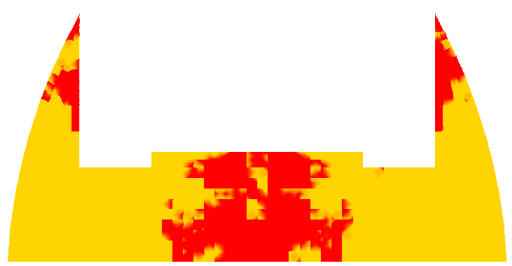

(k) $\sigma_{s}$, high

Fig. 4: Phenotypes after 24 iterations. Influence of fibre stimulus and material parameters. No bone is predicted to form.

\section{Results}

In all simulations a mixture of cartilage and fibrous tissue is predicted within the fracture callus, with no bone formation. Similar patterns of tissue differentiation are predicted by the classic isotropic model and the anisotropic model with "low" material parameters (see figures $4 \mathrm{a}$ to $4 \mathrm{k}$ ). Higher soft tissue stiffness values lead to the prediction of less cartilage formation. Area fractions of fibrous tissue are predicted to increase from $55.4 \%(\boldsymbol{C}$, low $)$ to $80.6 \%(\boldsymbol{C}$, high $)$, see fig. 9. This is caused by higher fluid velocities within the callus (see figs. 5c to 5k for comparison). The predicted fibre angles and circular standard deviations are summarised in table 2 for the outer and inner regions, respectively. A visual impression of the fibre architecture can be obtained in Fig. 6. The collagen fibre orientation is predicted to change from $\approx 1.5^{\circ}$ in the superficial zone to between $35^{\circ}$ and $60^{\circ}$ in the deep zone, depending on the considered stimulus. Circular standard deviations in the regions of interest increased strongly from superficial to deep zones as was also observed in Cullinane et al (2002). Generally, all regulatory stimuli were able to capture this fundamental trend in the fibre architecture, although certain variations were observed that are described below. The strain driven model predicted a more gradual increase of the fibre angle throughout the depth of the tissue. On the other hand the stress controlled model predicted rapid changes in fibre orientation and also predicted higher angles in the deep zones (see figs. 8a to 8c). The transition from parallel to perpendicular orientation occurred more towards the lower middle zone when $\boldsymbol{\sigma}_{s}$ was chosen as the stimulus. For the other stimuli, the reorientation occurred mostly in the deep zone. Total solid stress driven remodelling also predicted a peak fibre angle between middle and 


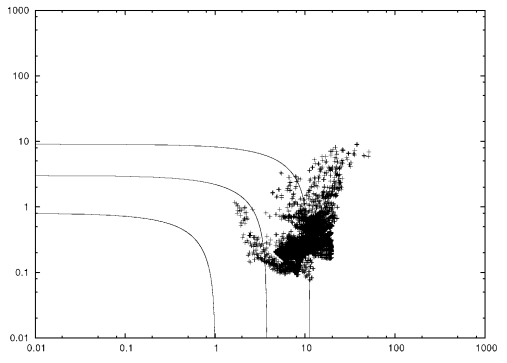

(a) all, day 1

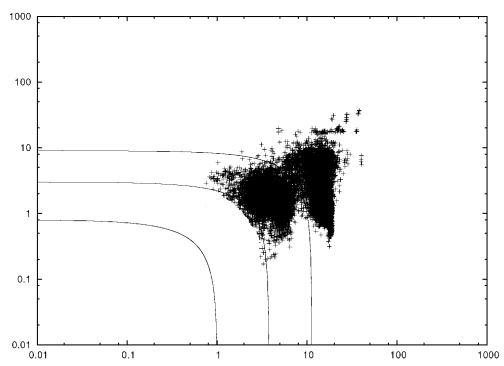

(c) $\boldsymbol{C}$, low, day 24

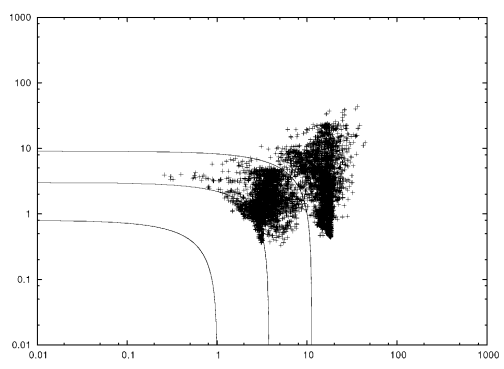

(f) $\boldsymbol{\sigma}_{s}^{E}$, low, day 24

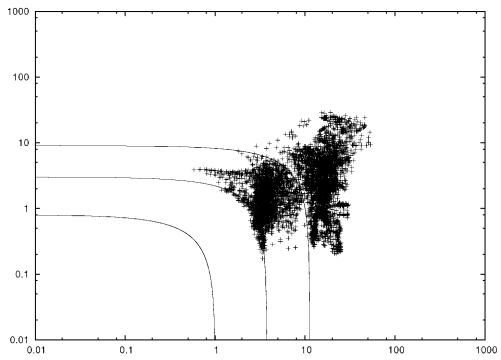

(i) $\boldsymbol{\sigma}_{s}$, low, day 24

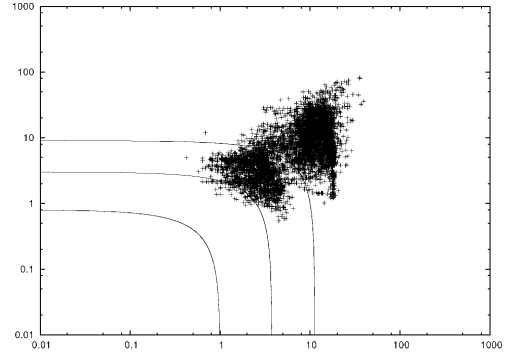

(d) $\boldsymbol{C}$, mid, day 24

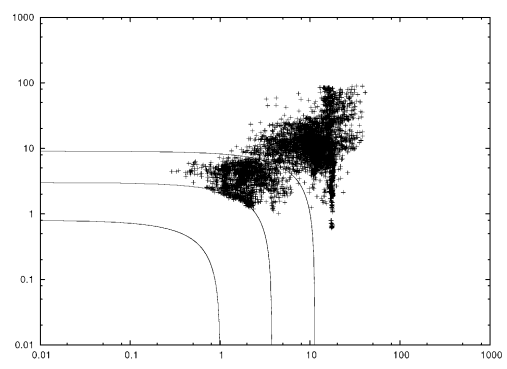

(g) $\boldsymbol{\sigma}_{s}^{E}$, mid, day 24

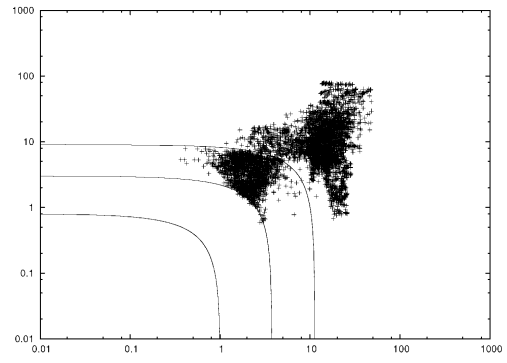

(j) $\boldsymbol{\sigma}_{s}$, mid, day 24

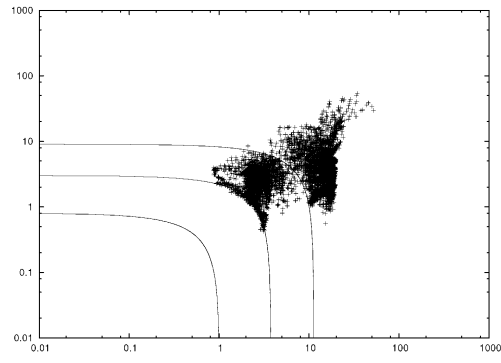

(b) isotropic, high, day 24

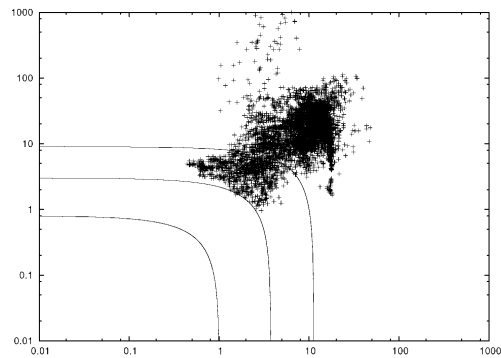

(e) $\boldsymbol{C}$, high, day 24

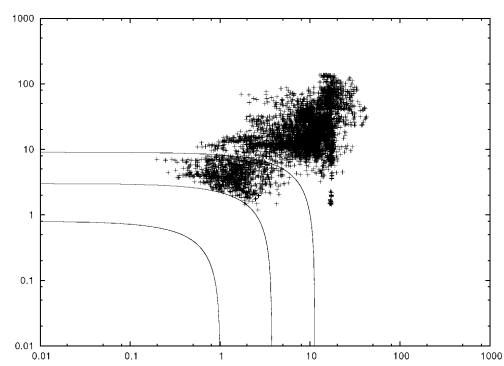

(h) $\boldsymbol{\sigma}_{s}^{E}$, high, day 24

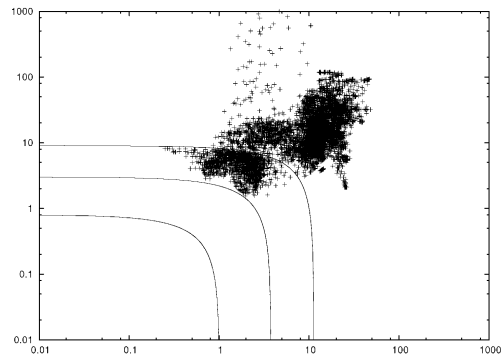

(k) $\boldsymbol{\sigma}_{s}$, high, day 24

Fig. 5: Relative influence of stimuli at iteration 24 (octahedral shear strain on $\mathrm{x}$-axis [\%], fluid velocity on $\mathrm{y}$-axis [ $\mu \mathrm{m}]$, double logarithmic scale). Iteration one is identical for all simulations.

deep zone followed by a drop towards the deep zone (see Fig. 8b). The other stimuli did not exhibit this pronounced behaviour.

In both the outer and inner region of the internal callus (see Fig. 3), the models predict an architecture with fibres parallel to the transverse plane in the superficial zone. In the middle zone the strain driven algorithm predicted similar angles in inner and outer re- gions, whereas a the angle changed from $-1.8^{\circ}$ in the inner region to $9.8^{\circ}$ in the outer region for the extra stress driven algorithm. When the total solid stress was used as fibre stimulus the angle doubled from outer to inner region. In the deep zones a large drop in the fibre angle was predicted during strain driven remodelling from $46.4^{\circ}$ to $24.6^{\circ}$ between the outer and inner region. During stress driven remodelling the trend was not as 


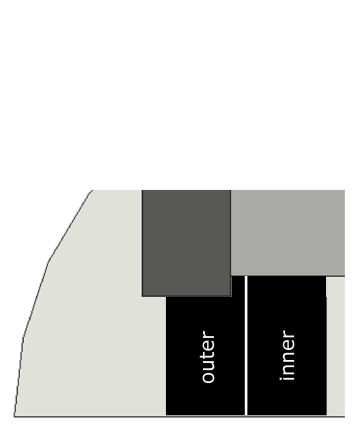

internal callus

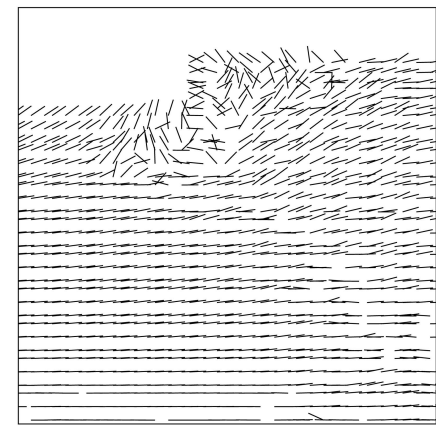

(a) $C$

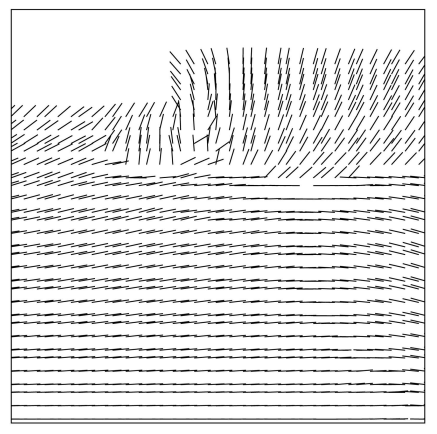

(b) $\sigma_{s}^{E}$

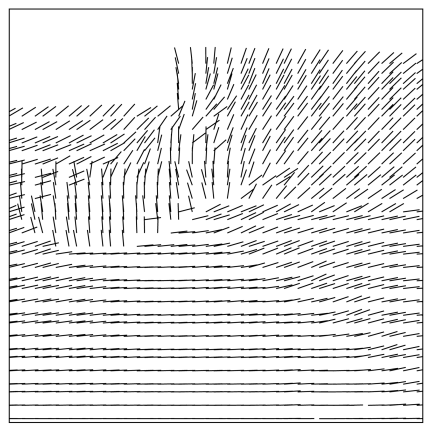

(c) $\sigma_{s}$

Fig. 6: Predicted fibre orientations for the three stimuli after 24 days of loading in the internal callus. Figure on left hand side shows the regions defined as the "inner" and "outer" in the internal callus (separated by the white line).

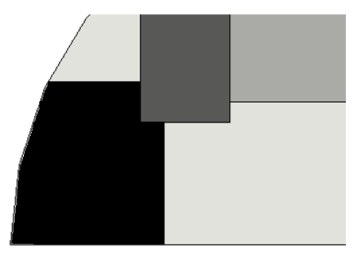

external callus

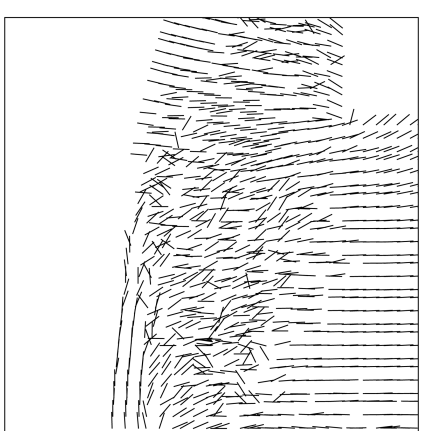

(a) $C$

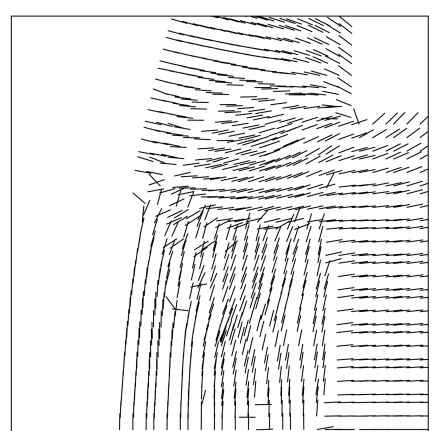

(b) $\boldsymbol{\sigma}_{s}^{E}$

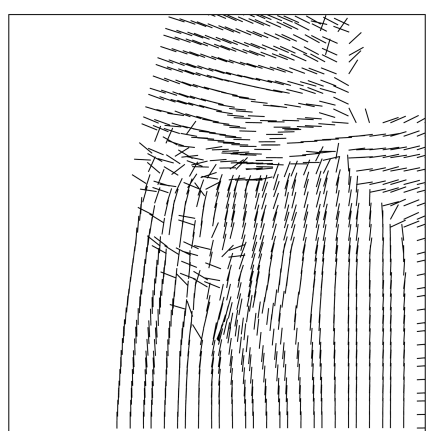

(c) $\sigma_{s}$

Fig. 7: Predicted fibre orientations for the three stimuli after 24 days of loading in the external callus (region filled in with black in figure on left hand side).

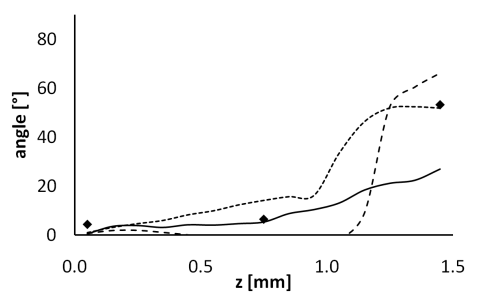

(a) inner region

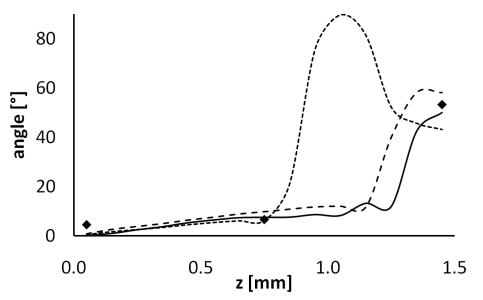

(b) outer region

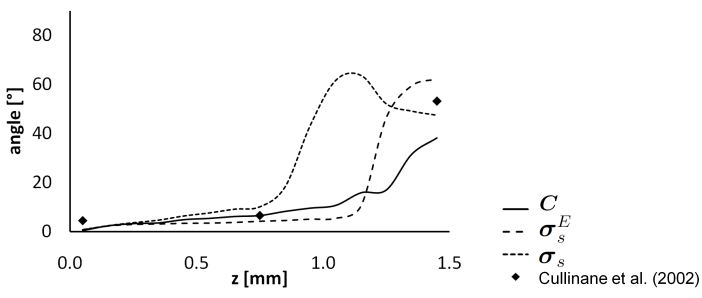

(c) combined

Fig. 8: Average fibre angles at iteration 24 throughout the depth of the repair tissue in the inner region, outer region and both regions combined. The coordinate $z$ is counted positive in proximal direction along the bone axis with $z=0$ at the transverse mid plane of the fracture callus (superficial zone).

severe and opposite, with an increase from the outer to the inner region predicted.

Increasing the soft tissue stiffness values from the baseline values leads to changes in the predicted fibre angle in deep zones (see table 2). This is most pronounced for strain driven remodelling. Only minimal changes in the predicted fibre angles were observed in the superficial zone retaining the general result of a fibre orientation parallel to the transverse plane for all stimuli.
Total solid stress driven remodelling of the fibre architecture was least sensitive to changes in the stiffness. This was the only stimulus to retain high deep zone angles througout the parameter variation.

The fibre architecture in the repair tissue of the external callus was also predicted (see Fig. 7). While all stimuli predict vertical fibre arrangement to some degree, strain driven remodelling predicted a more disorganised tissue. In contrast stress driven remodelling exhibits a 


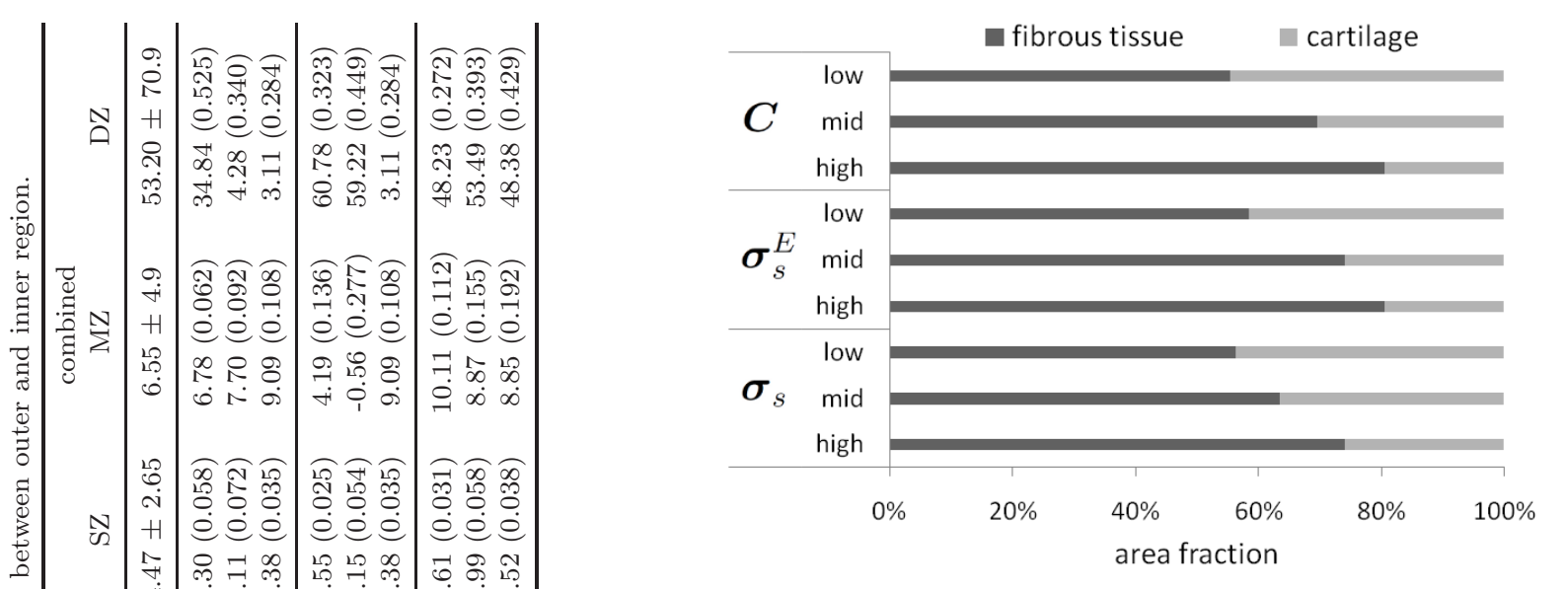

Fig. 9: Area fractions of fibrous tissue and cartilage in the fracture callus for the performed simulations after 24 iterations.

highly organised vertical fibre alignment in the direction of maximum tensile stresses during bending.

\section{Discussion}

In this paper we extended the mechano-regulation algorithm proposed by Prendergast et al (1997) to predict changes in tissue architecture during differentiation. Towards this end we implemented a large strain anisotropic biphasic material model and added a rule for collagen fibre organisation depending on the mechanical environment. Switching from an isotropic to a fibre reinforced constitutive model led to a reconsideration of material parameters normally used in mechanoregulation models. A parameter variation study revealed that a set of material parameters in the range of the soft tissues' equilibrium properties produced tissue differentiation predictions that were similar to those determined by making the assumption of tissue isotropy. The tensile moduli of this set were equal to the moduli used in previous isotropic studies. Of greater importance was the fact that this novel constitutive framework allowed for a fundamental investigation of the role of the local mechanical environment in regulating the architecture of regenerating soft tissue.

The model predictions of tissue differentiation for the non-union of a fracture subject to cyclic bending loads can be compared to histological data from developing neoarthroses (Cullinane et al, 2002). The mechanoregulation algorithm predicted a mixture of cartilaginous and fibrous tissue, generally consistent with experimental findings and previous computational models (Cullinane et al, 2002, 2003; Hayward and Morgan, 2009). However we did not predict the bony arcade structures reported by Cullinane et al (2002). Both 
strain- and stress-driven remodelling predicted collagen fibre angles similar to those measured throughout superficial, intermediate and deep zones of the neoarthroses, recapitulating the fibre architecture of native articular cartilage (Cullinane et al, 2002). This study demonstrates for the first time that mechano-regulation models can be used to successfully predict both tissue differentiation and organisation during fracture repair. This provides further evidence that the collagen organisation of the repair tissue is regulated by the local mechanical environment.

Predicted fibre orientations were least sensitive to material parameter variation when based on $\boldsymbol{\sigma}_{s}$. With this stress type stimuli we also observed the lowest deviation in predictions of fibre architecture between the inner and outer regions. However, there was no data available on these deviations in experimental studies (Cullinane et al, 2002).

The external callus is dominated by highly aligned vertical fibres during stress driven remodelling (Fig. 7). Those fibres may contribute to a stabilisation of the fracture by supporting tensile stresses during bending. The strain driven algorithm predicted a more disorganised tissue due to lateral strains occurring during compressive loading. Vertical alignment can still be seen, however in a smaller area (Fig. 7).

As expected, higher stiffness values for the soft tissues in tension and compression lead to an increase in the calculated pore pressure values and gradients. These pressure gradients drive the fluid flow in the biphasic mixture leading to an increase in the stimulus for differentiation $S$ (eq. (10)), thus leading to more fibrous tissue being predicted by the mechano-regulation algorithm. The parameter set "low" yielded comparable results to the isotropic model predictions. During compression of a biphasic medium lateral tensile strains can occur. Thus, though fibres only bear load during tensile loading in the described material model, depending on their orientation fibres can contribute to the overall apparent stiffness of a compressed piece of tissue. The fibres then support fluid pressurisation. If this induced pressure is non-homogeneous, i.e. $\boldsymbol{\nabla} p \neq \mathbf{0}$, it will elevate the fluid flow induced stimuli experienced by the cells.

While both stress and strain driven remodelling algorithms have been proposed, one should keep in mind that either are but mathematical, not physical, concepts. Due to their phenomenological nature their validity must be supported by application to various different scenarios and comparison to experimental data. Though the angles predicted by stress driven remodelling in this study are slightly closer to the measured ones and were influenced less by the parameter varia- tion, this result is not sufficient to make any kind of statement in that direction. Comparison of both stresstype stimuli shows quite similar values in the predicted architecture. This result can not be generalised to all scenarios. In a mechanical environment where the hydrostatic pressure is high compared to the solid matrix extra stress, the total stress in the solid will be quite different from that extra stress and will predict a different fibre architecture.

The employed model had some limitations: The fracture was modelled as a two dimensional structure to reduce calculation times. We also used an idealised geometry rather than experiment specific data. These two simplifications are likely contributing to the lack of bone formation predicted in our models compared to that observed in the experimental study (Cullinane et al, 2002). The intrinsic viscoelasticity of the involved soft tissues was neglected. We furthermore did not model angiogenesis (Geris et al, 2006; Checa and Prendergast, 2009b) because the developing neoarthrosis and not bone formation was the focus of interest. Stem cell dispersal as a combination of proliferation and migration was implemented as a simple diffusive process without accounting for cell death or the biochemical environment (such as growth factors, e.g. Bailón-Plaza and van der Meulen (2001)). The model assumes that all MSCs migrated into the callus from the bone marrow, the periosteum and the outer cortical surface and neglects other MSCs that may home into the injured site from alternative sources. Furthermore, it assumes that all MSCs will respond identically to their mechanical environment, whereas in reality the bone marrow cell population in itself is highly heterogeneous. Cellular events and characteristics can be captured more accurately with extended continuum models (Andreykiv et al, 2008; Isaksson et al, 2008b,a) or lattice based approaches including stochastic components (Perez and Prendergast, 2007; Byrne et al, 2007; Checa and Prendergast, 2009a). Callus growth was not considered, but has been incorparated into other models (Gómez-Benito et al, 2005, 2006; García-Aznar et al, 2007). Tissue damage was not included in the mechano-regulation model, but would be considered likely in regions of high strain. Despite these limitations the model was able to capture the main experimental results and predict the zonal architecture of the developing cartilage. Future tests of the hypotheses made in the model could include attempts to simulate healing under altered loading conditions and fracture gap sizes. Another aspect we wish to improve in the near future is related to the time course of the healing: Presently all tissues and components are synthesised at the same rate. However, a composition based approach (e.g. Wilson et al 
(2007, 2006b); Loboa et al (2003)) with cell-specific activities (such as for example demonstrated in Isaksson et al (2008b)) will be more suitable to capture such effects like age, species and tissue specific synthesis rates. To ease parameter identification we used a linear fibre model $\left(\beta_{a}=\beta_{g} \equiv 0\right)$ which does not capture the typical stretch induced stiffening of collagen molecules. Fibre dispersion was not included in our remodelling considerations, as has been done in other remodelling algorithms (Driessen et al, 2008). Other interesting aspects that may be considered include the distinction between remodelling existing and the synthesis of new tissue. In the future this model can be applied to investigate specifically those healing processes and tissue engineering strategies where recapitulating normal tissue architecture is important. For example chondral and osteochondral defect repair critically depends on achieving a native-like zonal structure so that the tissue can endure in-vivo loads. However, in this first study we focused on the integration of fibre synthesis and organisation with an existing theory for mechano-regulated tissue differentiation. We provided evidence that mechanoregulation algorithms can be combined with knowledge from remodelling studies to simultaneously address the differentiation and organisation of regenerating tissues. It is expected that the mechano-regulation algorithms will become more powerful tools by considering not only changes in phenotype during regenerative processes but also tissue architecture.

Acknowledgements We thank Andy Bell from MSC support for his help and MSC for special user subroutines. Prof. Hubert Günther and Dr. Uwe-Jens Görke for their help with constitutive theory. Finally we acknowledge funding from IRCSET (G30345) and the President of Ireland Young Researcher Award (08/YI5/B1336).

\section{References}

Akizuki S, Mow VC, Muller F, Pita JC, Howell DS (1987) Tensile properties of human knee joint cartilage. ii. correlations between weight bearing and tissue pathology and the kinetics of swelling. J Orthop Res 5(2):173-186, DOI 10.1002/jor.1100050204, URL http://dx.doi.org/10.1002/jor.1100050204

Andreykiv A, van Keulen F, Prendergast PJ (2008) Simulation of fracture healing incorporating mechanoregulation of tissue differentiation and dispersal/proliferation of cells. Biomech Model Mechanobiol 7(6):443461, DOI 10.1007/s10237-007-0108-8, URL http://dx.doi.org/10.1007/s10237-007-0108-8
Bailón-Plaza A, van der Meulen M (2001) A mathematical framework to study the effects of growth factor influences on fracture healing. Journal of Theoretical Biology 212(2):191 - 209, DOI DOI:10.1006/jtbi.2001.2372, URL http://www.sciencedirect.com/ science/article/B6WMD-457VD8R-4G/2/ 9713489c72b7712ab8fea9380b22cde7

Boccaccio A, Pappalettere C, Kelly DJ (2007) The influence of expansion rates on mandibular distraction osteogenesis: a computational analysis. Ann Biomed Eng 35(11):1940-1960, DOI 10.1007/ s10439-007-9367-x, URL http://dx.doi.org/10. 1007/s10439-007-9367-x

Boccaccio A, Lamberti L, Pappalettere C, Cozzani M, Siciliani G (2008) Comparison of different orthodontic devices for mandibular symphyseal distraction osteogenesis: a finite element study. Am J Orthod Dentofacial Orthop 134(2):260-269, DOI 10.1016/j.ajodo.2006.09.066, URL http://dx.doi. org $/ 10.1016 / \mathrm{j}$. ajodo.2006.09.066

Byrne DP, Lacroix D, Planell JA, Kelly DJ, Prendergast PJ (2007) Simulation of tissue differentiation in a scaffold as a function of porosity, young's modulus and dissolution rate: application of mechanobiological models in tissue engineering. Biomaterials 28(36):5544-5554, DOI 10.1016/j.biomaterials. 2007.09.003, URL http://dx.doi.org/10.1016/j. biomaterials.2007.09.003

Carter DR, Blenman PR, Beauprcé GS (1988) Correlations between mechanical stress history and tissue differentiation in initial fracture healing. J Orthop Res 6(5):736-748, DOI 10.1002/jor.1100060517, URL http://dx.doi.org/10.1002/jor.1100060517

Carter DR, Beauprcé GS, Giori NJ, Helms JA (1998) Mechanobiology of skeletal regeneration. Clin Orthop Relat Res (355 Suppl):S41-S55

Checa S, Prendergast P (2009a) A mechanobiological model for tissue differentiation that includes angiogenesis: A lattice-based modeling approach. Annals of Biomedical Engineering 37(1):129-145, URL http://dx.doi.org/10.1007/s10439-008-9594-9

Checa S, Prendergast PJ (2009b) A mechanobiological model for tissue differentiation that includes angiogenesis: a lattice-based modeling approach. Ann Biomed Eng 37(1):129-145, DOI 10. 1007/s10439-008-9594-9, URL http://dx.doi .org/ 10.1007/s10439-008-9594-9

Claes LE, Heigele CA (1999) Magnitudes of local stress and strain along bony surfaces predict the course and type of fracture healing. J Biomech 32(3):255-266

Claes LE, Heigele CA, Neidlinger-Wilke C, Kaspar D, Seidl W, Margevicius KJ, Augat P (1998) Effects of 
mechanical factors on the fracture healing process. Clin Orthop Relat Res (355 Suppl):S132-S147

Cullinane DM, Fredrick A, Eisenberg SR, Pacicca D, Elman MV, Lee C, Salisbury K, Gerstenfeld LC, Einhorn TA (2002) Induction of a neoarthrosis by precisely controlled motion in an experimental midfemoral defect. J Orthop Res 20(3):579-586, DOI 10. 1016/S0736-0266(01)00131-0, URL http://dx. doi. org/10.1016/S0736-0266(01)00131-0

Cullinane DM, Salisbury KT, Alkhiary Y, Eisenberg S, Gerstenfeld L, Einhorn TA (2003) Effects of the local mechanical environment on vertebrate tissue differentiation during repair: does repair recapitulate development? J Exp Biol 206(Pt 14):2459-2471

Driessen NJB, Boerboom RA, Huyghe JM, Bouten CVC, Baaijens FPT (2003a) Computational analyses of mechanically induced collagen fiber remodeling in the aortic heart valve. Journal of Biomechanical Engineering 125(4):549-557, DOI 10.1115/1.1590361, URL http://link.aip.org/link/?JBY/125/549/1

Driessen NJB, Peters GWM, Huyghe JM, Bouten CVC, Baaijens FPT (2003b) Remodelling of continuously distributed collagen fibres in soft connective tissues. J Biomech 36(8):1151-1158

Driessen NJB, Bouten CVC, Baaijens FPT (2005) Improved prediction of the collagen fiber architecture in the aortic heart valve. J Biomech Eng 127(2):329-336

Driessen NJB, Cox MAJ, Bouten CVC, Baaijens FPT (2008) Remodelling of the angular collagen fiber distribution in cardiovascular tissues. Biomech Model Mechanobiol 7(2):93-103, DOI 10. 1007/s10237-007-0078-x, URL http://dx.doi.org/ $10.1007 / \mathrm{s} 10237-007-0078-\mathrm{x}$

Fisher NI (1993) Statistical analysis of circular data. Cambridge University Press

García-Aznar JM, Kuiper JH, Gómez-Benito MJ, Doblaré M, Richardson JB (2007) Computational simulation of fracture healing: influence of interfragmentary movement on the callus growth. J Biomech 40(7):1467-1476, DOI 10.1016/j.jbiomech. 2006.06.013, URL http://dx.doi.org/10.1016/j. jbiomech.2006.06.013

Garikipati K, Arruda EM, Grosh K, Narayanan H, Calve S (2004) A continuum treatment of growth in biological tissue: the coupling of mass transport and mechanics. Journal of the Mechanics and Physics of Solids 52(7):1595 - 1625, DOI DOI:10.1016/j.jmps.2004.01.004, URL http://www.sciencedirect.com/ science/article/B6TXB-4BV4PW5-1/2/ b94b1174d8b02f1709a495f8bae22bc2

Garikipati K, Olberding J, Narayanan H, Arruda E, Grosh K, Calve S (2006) Biological remod- elling: Stationary energy, configurational change, internal variables and dissipation. Journal of the Mechanics and Physics of Solids 54(7):1493 - 1515, DOI DOI:10.1016/j.jmps.2005.11.011, URL http://www.sciencedirect.com/ science/article/B6TXB-4J9MV5T-1/2/

b3086bf cb28b11b9b94379805b44cc0e

Geris L, Sloten JV, Oosterwyck HV (2006) Mathematical modeling of bone regeneration including the angiogenic process. Journal of Biomechanics 39(Supplement 1):S411 S412, DOI DOI:10.1016/S0021-9290(06)84671-3, URL http://www.sciencedirect.com/ science/article/B6T82-4KR88PB-28G/2/

bfa4556efcc77303ea8f535ccbe8049b, abstracts of the 5th World Congress of Biomechanics

Giori NJ, Beaupr GS, Carter DR (1993) Cellular shape and pressure may mediate mechanical control of tissue composition in tendons. J Orthop Res 11(4):581591, DOI 10.1002/jor.1100110413, URL http://dx. doi.org/10.1002/jor.1100110413

Gleason RL, Humphrey JD (2004) A mixture model of arterial growth and remodeling in hypertension: altered muscle tone and tissue turnover. J Vasc Res 41(4):352-363, DOI 10.1159/000080699, URL http: //dx.doi.org/10.1159/000080699

Gómez-Benito MJ, García-Aznar JM, Kuiper JH, Doblaré M (2005) Influence of fracture gap size on the pattern of long bone healing: a computational study. J Theor Biol 235(1):105-119, DOI 10.1016/j.jtbi. 2004.12.023, URL http://dx.doi.org/10.1016/j. jtbi.2004.12.023

Gómez-Benito MJ, García-Aznar JM, Kuiper JH, Doblaré M (2006) A 3d computational simulation of fracture callus formation: influence of the stiffness of the external fixator. J Biomech Eng 128(3):290-299, DOI 10.1115/1.2187045, URL http://dx.doi.org/ 10.1115/1.2187045

Hariton I, de Botton G, Gasser TC, Holzapfel GA (2007a) Stress-driven collagen fiber remodeling in arterial walls. Biomech Model Mechanobiol 6(3):163175, DOI 10.1007/s10237-006-0049-7, URL http: //dx.doi.org/10.1007/s10237-006-0049-7

Hariton I, deBotton G, Gasser TC, Holzapfel GA (2007b) Stress-modulated collagen fiber remodeling in a human carotid bifurcation. $\mathrm{J}$ Theor Biol 248(3):460-470, DOI 10.1016/j.jtbi.2007.05.037, URL http://dx.doi.org/10.1016/j.jtbi.2007. 05.037

Hayward L, Morgan E (2009) Assessment of a mechanoregulation theory of skeletal tissue differentiation in an in vivo model of mechanically induced cartilage formation. Biomech Model Mechanobiol DOI 10. 
1007/s10237-009-0148-3, URL http: //dx . doi.org/ $10.1007 / \mathrm{s} 10237-009-0148-3$

Holzapfel G, Gasser T, Ogden R (2002) A new constitutive framework for arterial wall mechanics and a comparative study of material models. Cardiovascular Soft Tissue Mechanics pp 1-48, URL http: //dx.doi .org/10.1007/0-306-48389-0\_1

Huang CY, Stankiewicz A, Ateshian GA, Mow VC (2005) Anisotropy, inhomogeneity, and tensioncompression nonlinearity of human glenohumeral cartilage in finite deformation. J Biomech 38(4):799-809, DOI 10.1016/j.jbiomech.2004.05.006, URL http:// dx.doi.org/10.1016/j.jbiomech.2004.05.006

Huiskes R, Driel WDV, Prendergast PJ, Søballe K (1997) A biomechanical regulatory model for periprosthetic fibrous-tissue differentiation. J Mater Sci Mater Med 8(12):785-788

Humphrey JD, Rajagopal KR (2003) A constrained mixture model for arterial adaptations to a sustained step change in blood flow. Biomech Model Mechanobiol 2(2):109-126, DOI 10.1007/ s10237-003-0033-4, URL http://dx.doi.org/10. 1007/s10237-003-0033-4

Isaksson $\mathrm{H}$, van Donkelaar CC, Huiskes $\mathrm{R}$, Ito $\mathrm{K}$ (2006a) Corroboration of mechanoregulatory algorithms for tissue differentiation during fracture healing: Comparison with in vivo results. J Orthop Res 24(5):898-907, DOI 10.1002/jor.20118, URL http: //dx.doi.org/10.1002/jor. 20118

Isaksson H, Wilson W, van Donkelaar CC, Huiskes R, Ito K (2006b) Comparison of biophysical stimuli for mechano-regulation of tissue differentiation during fracture healing. J Biomech 39(8):1507-1516, DOI 10.1016/j.jbiomech.2005.01.037, URL http:// dx.doi.org/10.1016/j.jbiomech.2005.01.037

Isaksson H, Comas O, van Donkelaar CC, Mediavilla J, Wilson W, Huiskes R, Ito K (2007) Bone regeneration during distraction osteogenesis: mechanoregulation by shear strain and fluid velocity. J Biomech 40(9):2002-2011, DOI 10.1016/j.jbiomech. 2006.09.028, URL http://dx.doi.org/10.1016/j . jbiomech.2006.09.028

Isaksson $\mathrm{H}$, van Donkelaar CC, Huiskes $\mathrm{R}$, Ito $\mathrm{K}$ (2008a) Corrigendum to a mechano-regulatory bone-healing model incorporating cell-phenotype specific activity : [j. theor. biol. 252 (2008) 230246]. Journal of Theoretical Biology 254(3):717 - 717, DOI DOI:10.1016/j.jtbi.2008.07.003, URL http://www.sciencedirect.com/ science/article/B6WMD-4SYCR1P-1/2/ cf015f26dd844846ac59e30a31552f bf

Isaksson $\mathrm{H}$, van Donkelaar CC, Huiskes $\mathrm{R}$, Ito $\mathrm{K}$ (2008b) A mechano-regulatory bone-healing model incorporating cell-phenotype specific activity. J Theor Biol 252(2):230-246, DOI 10.1016/j.jtbi. 2008.01.030, URL http://dx.doi.org/10.1016/j . jtbi. 2008.01 .030

Jurvelin JS, Buschmann MD, Hunziker EB (1997) Optical and mechanical determination of poisson's ratio of adult bovine humeral articular cartilage. J Biomech 30(3):235-241

Kelly DJ, Prendergast PJ (2005) Mechano-regulation of stem cell differentiation and tissue regeneration in osteochondral defects. J Biomech 38(7):1413-1422, DOI 10.1016/j.jbiomech.2004.06.026, URL http:// dx.doi.org/10.1016/j.jbiomech.2004.06.026

Kelly DJ, Prendergast PJ (2006) Prediction of the optimal mechanical properties for a scaffold used in osteochondral defect repair. Tissue Eng 12(9):25092519, DOI 10.1089/ten.2006.12.2509, URL http:// dx.doi.org/10.1089/ten.2006.12.2509

Kuhl E, Holzapfel G (2007) A continuum model for remodeling in living structures. Journal of Materials Science 42(21):8811-8823, URL http://dx . doi. org/10.1007/s10853-007-1917-y

Lacroix D, Prendergast P (2000) A homogenization procedure to prevent numerical instabilities in poroelastic tissue differentiation models. In: Eighth Annual Symposium: Computational Methods in Orthopaedic Biomechanics, Orlando, FL

Lacroix D, Prendergast PJ (2002a) A mechanoregulation model for tissue differentiation during fracture healing: analysis of gap size and loading. J Biomech 35(9):1163-1171

Lacroix D, Prendergast PJ (2002b) Three-dimensional simulation of fracture repair in the human tibia. Comput Methods Biomech Biomed Engin 5(5):369376, DOI 10.1080/1025584021000025014, URL http: //dx.doi.org/10.1080/1025584021000025014

Lacroix D, Prendergast PJ, Li G, Marsh D (2002) Biomechanical model to simulate tissue differentiation and bone regeneration: application to fracture healing. Med Biol Eng Comput 40(1):14-21

Loboa EG, Beaupr GS, Carter DR (2001) Mechanobiology of initial pseudarthrosis formation with oblique fractures. Journal of Orthopaedic Research 19(6):1067-1072, URL http://dx.doi.org/ 10.1016/S0736-0266(01)00028-6

Loboa EG, Wren TAL, Beauprcé GS, Carter DR (2003) Mechanobiology of soft skeletal tissue differentiation-a computational approach of a fiber-reinforced poroelastic model based on homogeneous and isotropic simplifications. Biomech Model Mechanobiol 2(2):83-96, DOI 10.1007/ s10237-003-0030-7, URL http://dx.doi.org/10. $1007 /$ s10237-003-0030-7 
Mow VC, Guo XE (2002) Mechano-electrochemical properties of articular cartilage: their inhomogeneities and anisotropies. Annu Rev Biomed Eng 4:175-209, DOI 10.1146/annurev.bioeng.4. 110701.120309, URL http://dx.doi.org/10.1146/ annurev. bioeng. 4.110701.120309

Mow VC, Kuei SC, Lai WM, Armstrong CG (1980) Biphasic creep and stress relaxation of articular cartilage in compression? theory and experiments. J Biomech Eng 102(1):73-84

MSC (2008a) Marc 2008r1 - Volume A: Theory and User Information. MSC.Software Corporation, 2 MacArthur Place, Santa Ana, CA 92707, USA, URL www.mscsof tware.com

MSC (2008b) Marc 2008r1 - Volume B: Element Library. MSC.Software Corporation, 2 MacArthur Place, Santa Ana, CA 92707, USA, URL www. mscsoftware.com

Pauwels F (1941) Grundri einer biomechanik der frakturheilung. In: 34. Kongre der Deutschen Orthopädischen Gesellschaft., Ferdinand Enke Verlag, Stuttgart., (Biomechanics of the Locomotor Apparatus. Translated by Manquet, P., Furlong, R., (Eds.), 1980, Springer, Berlin, 375-407).

Pauwels F (1960) Eine neue Theorie über den Einflu mechanischer Reize auf die Differenzierung der Stützgewebe. Anatomy and Embryology 121(6):478-515, URL http: //dx.doi.org/10.1007/BF00523401

Perez M, Prendergast P (2007) Random-walk models of cell dispersal included in mechanobiological simulations of tissue differentiation. URL http://linkinghub.elsevier.com/retrieve/ pii/S0021929006003988

Prendergast P, Huiskes R, Sballe K (1997) Esb research award 1996. biophysical stimuli on cells during tissue differentiation at implant interfaces. J Biomech 30(6):539-548

Roth V, Mow VC (1980) The intrinsic tensile behavior of the matrix of bovine articular cartilage and its variation with age. J Bone Joint Surg Am 62(7):11021117

Taber LA, Humphrey JD (2001) Stress-modulated growth, residual stress, and vascular heterogeneity. J Biomech Eng 123(6):528-535

Wilson W, Driessen NJB, van Donkelaar CC, Ito K (2006a) Prediction of collagen orientation in articular cartilage by a collagen remodeling algorithm. Osteoarthritis Cartilage 14(11):1196-1202, DOI 10. 1016/j.joca.2006.05.006, URL http://dx.doi.org/ $10.1016 / j$.joca. 2006.05 .006

Wilson W, Huyghe JM, van Donkelaar CC (2006b) A composition-based cartilage model for the assessment of compositional changes during cartilage damage and adaptation. Osteoarthritis Cartilage 14(6):554560, DOI 10.1016/j.joca.2005.12.006, URL http:// dx.doi.org/10.1016/j.joca.2005.12.006

Wilson W, Huyghe JM, van Donkelaar CC (2007) Depth-dependent compressive equilibrium properties of articular cartilage explained by its composition. Biomech Model Mechanobiol 6(1-2):43-53, DOI 10. 1007/s10237-006-0044-z, URL http://dx.doi.org/ 10.1007/s10237-006-0044-z

Wren TA, Beaupr GS, Carter DR (2000) Mechanobiology of tendon adaptation to compressive loading through fibrocartilaginous metaplasia. J Rehabil Res Dev 37(2):135-143 